The lack of trained teachers in Panama is mainly one of salaries, although the problem of finding teachers for rural areas is similar to that in all countries with large urbanized districts. At present primary school teachers are trained in an up-to-date normal school; but there is little facility for training secondary school teachers. Many secondary school teachers have been employed on a part-time basis, but a 1946 law provides for full-time secondary teachers who must be registered.

The National University of Panama was opened in 1935 and by 1946 had 467 men students and 288 women. Its faculties are grouped as: Philosophy and Letters and Education, Law and Political Sciences, Public Administration and Commerce, Sciences, Medical Sciences, Engineering and Architecture, while government is by a General University Council, an Administrative Board and the Board of Trustees, an interesting feature being that student representatives sit on all three governing bodies. No tuition fees are charged to students, while all classes are held in the late afternoon and evening, the university buildings being used for other educational purposes during the rest of the day.

General cultural activities in Panama are represented by a national and forty-three branch libraries, a national conservatory of music and speech, a symphony orchestra, national school of painting, national theatre and national museum and monuments.

T. H. HAWkins

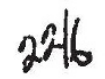

\section{ASTRONOMICAL NAVIGATION IN THE AIR}

A DISCUSSION of Prethods to produce speed 1 and accuracy in the practice of astronomical of was organised by the Institute of Navigation, ad held on June 17 in the lecture hall of the Rofal Geographical Society, under the chairmans 19 of the astronomer royal, Sir Harold Spfnct. Jones. In his introductory remarks Sir Hard directed attention to the fact that it was in the same hall, some twelve years earlier, that the Air Almanac had been first discussed in public.

The discussion was opened by Squadron Leader D. O. Fraser, who read a paper by Mr. J. B. Parker analysing the broad requirements of aids to air navigation. It is clear that 'astro' cannot fulfil the requirements of a universal aid for such specialized problems as homing and maintenance of traffic patterns ; since some such aid is necessary, a moderate accuracy (say a 95 per cent error of 10 nautical miles) will suffice for 'astro'. Mr. Parker then went on to advocate a simplification of the Air Almanac and reduction tables comparable to the modified require. ments.

Mr. A. H. Jessell proceeded to discuss the general problems arising in high-speed flight and the sort of sextant suitable for rapid fixing in pressure-cabin aircraft. He suggested the possibility of some form of automatic astro-compass for pilot use and improvements in optical systems so as to make star observations possible in day-time. This would then enable star curves to be used both by night and day; printed on a small scale, appropriate to the actual accuracy obtainable in the air, these would allow the sky to be mapped in a relatively small number of sheets.
Mr. D. H. Sadler briefly surveyed the various stages between observation and fix, and summarized existing methods. The astrograph (compare the suggested star curves) is the ideal instrument in principle, but cannot be readily applied to the sun, moon or planets. He therefore examined the possibility of (1) an altitude-azimuth almanac and (2) an almanac tabulating Aquino's $a$ and $b$; even with special methods of non-linear interpolation, long intercepts and the reduced accuracy (about $5^{\prime}$ ) comparable with Parker's requirements, neither almanac offers any substantial advantage over the existing methods.

Then, a position line protractor for use with long intercepts was described by Mr. P. F. Everitt. Constructed on a stereographic projection to a scale of $1: 3$ million, it can be used to draw curved position lines on both the stereographic and, without appreciable error, the Lambert conformal projections. The use of such an instrument would enable considerable reduction to be made in the size of altitude-azimuth tables. He also suggested the precomputation of altitudes and azimuths by a ground staff before flight, with the navigator applying corrections for run and difference in time.

M. A. J. Bastien, who had made a special visit from France to take part in the discussion, read an interesting paper by his colleague, M. R. Genty, describing a method for solving the astronomical spherical triangle when the altitude and azimuth are both observed. A sextant for the simultaneous observation of these quantities (using Polaris or $\beta$ Hydri as reference for azimuth) has been made and gives promising results on the ground. A fix is ibtained simply by means of special tables.

The practicability of a system, first suggested by Captain Brett Hilder, for locating the zenith among the stars by photography was then discussed by Dr. R. d'E. Atkinson. He showed that it would be possible to determine a position simply and quickly by positioning the developed plate on suitable star charts. For the first time in the discussion he raised the unsolved problem of the definition of the vertical and suggested a method for the suspension of the camera, using a form of lazy-tongs linkage connecting two equal gyroscopes, as originally suggested by Mr. F. J. Hargreaves.

M. Bastien described in some detail the basic principles of an instrument which would record instant. aneously and continuously the latitude and longitude of an aircraft during flight, as deduced from stellar observations. The difficulties lie, however, in the practical details of the construction and operation, and it cannot be anticipated that such an instrument, giving a continuous geometrical solution, will be generally available in the near future.

A view, opposed to many of the previous speakers, was taken by Mr. Francis Chichester, who argued that a relatively high order of accuracy will be required from astronomical navigation to determine wind effect. He concluded that the principal failing at present is in the lack of a vertical datum and that, until a far more accurate solution of this problem has been established, it is a waste of effort to improve the other elements of the operation.

At the conclusion of these eight prepared papers, the chairman opened the meeting to general discussion. Captain R. C. Alabaster, in the course of comments on each of the papers, was quite definite that a lesser degree of accuracy cannot be accepted, and that an overall reduction in the time necessary 
to obtain a fix is essential if 'astro' is to survive as a premier aid to navigation. He welcomed the practical suggestions made, particularly the possibility of zenith photography, but reiterated the need for vertical stabilization.

The present state of the investigations into this problem was summarized by Mr. W. A. W. Fox, who briefly listed seven possible datums: free horizon, normal reflexion from water surface, haze levels, pressure isobaric levels, the magnetic field of the earth, cosmic rays, and the gravitational field of the earth. The first six are either of very limited application or involve great difficulties, thus leaving only the last. The Melville-Jones theorem (that the average altitude equals the true altitude if the track and ground speed at beginning and end of the run are the same) offers possibilities, but fatigue factor limits the use of the sextants. The perfect solution is the Schuler pendulum, of period 84 minutes-the same as that of the free earth; present attempts to make a gyro with a low wander-rate fall short by a factor of 100-1,000.

Dr. G. N. Harvey appealed for greater use of the magnetic field of the earth, both as a datum and as a position fixing system. Mr. T. H. O'Bierne suggested that the present bulk of tables for astronomical navigation can be substantially reduced by using optical methods of enlargement from very small figures or from microfilms. Wing Commander $\mathrm{E}$. Anderson compared 'astro' with radio methods, particularly the radio compass, and suggested that, if practicable, the whole basis of the information provided by 'astro' should be changed from position fixing to telling the navigator what to do. If the almanacs could tabulate altitude and azimuth for certain specific points (destinations), the navigator could utilize the principle of astro-ranges (analogous to radio-ranges or the use of the radio compass) to enable him to home. Such a method would have the advantage that its accuracy would increase as the destination was approached, and that individual observations could be continuously integrated. Squadron Leader D. Bower summarized practical experience in relation to the time taken by navigators to obtain a two- or three-star fix; he quoted figures of $25 \mathrm{~min}$. and $22 \mathrm{~min}$. for the relative times of obtaining a two-star fix with the Astronomical Navigation Tables and H.O. 249-reduced to 19 and 13 min. respectively when two navigators are carried,

\section{CONDUCTION IN GERMANIUM: THE TRANSISTOR}

CINCE the initia 1 publications by Bardeen and $\checkmark$ Brattain (s) Nature, Dec. 25, 1948, p. 982) on the transifor, several articles have appeared and talks hove been given by members of the Bell Teleph ne Laboratories staff describing in further detail the characteristics of the device and the theory of its action. Considerable progress has been made both in examination of the properties of the materials used and in the development of transistors for production. Various problems still remain to be solved, however, notably reduction in noise, and increase in the frequency limit, in addition to an improvement in the production of units with reproducible characteristics.

A comprehensive survey of the physical principles involved in transistor action, in which is included an outline of the history of the development, new data on the characteristics of the device, a discussion of the nature of electrical conduction in germanium and of the theory of the germanium point-contact rectifier, and an extensive detailed bibliography, has recently been given in the Physical Review (75, 1208-25; April 15, 1949) by the discoverers. The discussion is confined to the transistor, in which two contacts, the emitter and collector, are placed close to each other on one face of a germanium block; but the same principles are applicable to other geometrical arrangements, and to other semiconductors, for example silicon, on which some preliminary,work has already been done.

In the transistor there is a voltage gain and a power gain of an input signal, and possibly also a current amplification. The current multiplication factor (the rate of change of collector current with respect to emitter current at constant collector voltage) is, in typical units, of the order of 1-3. The dependence of this factor on bias voltage, frequency, temperature, and electrode spacing is discussed. Early experiments suggested that positive holes flow from the emitter to the collector along the surface of the germanium; but it has since been established that holes may flow either through the surface layer or through the body of the semiconductor. Estimates which are made of the orders of magnitude of the field produced by the collector current, the transit time for holes, the space charge produced by holes flowing into the collector, and the feedback resistance, confirm the general picture given of transistor action.

\section{APPOINTMENTS VACANT}

APPLICATIONS are inyited for the following appointments on or before the dates mentio led

GRADDATE LECTURH MATHEMATICS for Degree and Higher IN BrougieA SubJy cTS-The Principal, Central Technical College,

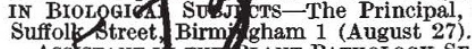

Suffolk street, Birm, gham 1 (August 27).
Ass diseas 1 of fruit and hops--The Secretary, East Malling Research diseas 0 fruit and hops-The Secretary, East

Assistant ChEMIST (Grade VI), an Assistant CHeMist (Grade V), an Assistant CHEMIST (Grade III), and an ASSISTANT CHEMIST (Grade I)-The Chief Engineer, Middlesex County Council Main Drainage Department, Isleworth, Middx., quoting F.909.T (August 29). ASSISTANT LECTURER IN HISTOLOGY AND EMBRYOLOGY-ThE Secretary, Royal Veterinary College and Hospital, Royal College Street, London, N.W.1 (August 31).

Assistant STATSTician in the Central Statistical office of the Town Clerk's Department-The Town Clerk, Room 30B, Counci House, Birmingham 1, endorsed 'Assistant Statistician' (September 2) SENIOR EXPERIMENTAL OFFICERS and EXPERMMENTAL OFFICERS for work connected with design and development of large wind tunnels and associated aerodynamic research equipment at the Royal Aircraft Establishment, Farnborough-The Technical and Scientifle Register (K), York House, Kingsway, London, W.C.2, quoting C.475/49A (September 3).

ASSISTANT LECTURER IN PHYSICS-The Secretary, St. Mary's Hospital Medical School, Paddington, W.2 (September 3).

Lecturer in Natural Phrlosophy in University College, Dundee - The Secretary, The University, St. Andrews (September 3).

CHEMIST as Deputy Municipal Analyst, Municipality of SingaporeMessrs. Peirce and Williams, 1 Victoria Street, London, S.W.1 (September 3).

ASSISTA NT IN ENTOMOLOGY with particular reference to ForestryThe Secretary, The University, Old College, South Bridge, Edinburgh (September 3).

PRINCIPAL SCIENTIFIC OFFICERS at the Royal Aircraft Establishment, Farnborough, (a) (Ref. C.470/49A) to carry out and supervise research into fatigue of aircraft structures, $(b)$ (Ref. C.471/49A) to take charge of section carrying out research into behaviour of materials and structural elements for use of aircraft designers, etc., $(c)$ (Ref C.472/49A) to carry out and supervise research into fundamenta theory of structures, primarily from the standpoint of aircraft-The Technical and Scientific Register (K), York House, Kin
W.C.2, quoting appropriate Ref. No. (September 5).

W.C.2, quoting appropriate Ref. No. (September 5).
SENYOR ScIENTIFIC OFFICER (with good degree in chemistry, physics, SENIOR ScIENTIFIC OFFICER (with good degree in chemistry, physics,
mathematics or engineering, together with research experience) in London under the Ministry of Supply, for scientific administration work, involving evaluation of scientiflc reports, advising administrativ staff, committee work, etc.-The Technical and Scientific Register (K), York House, Kingsway, London, W.C.2, quoting F.528/49A (Septem. ber 5 ). 